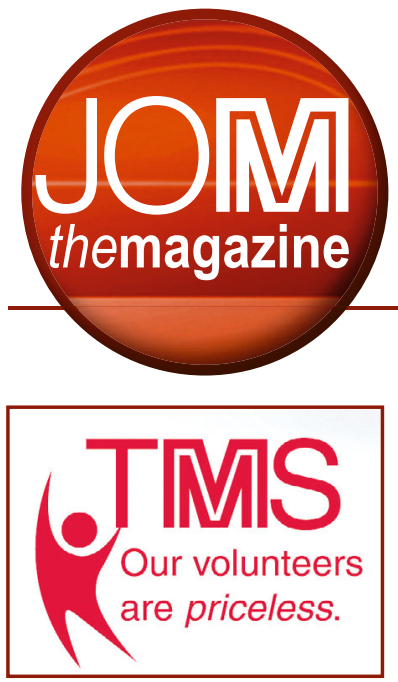

\title{
TMS volunteer face time
}

\section{Meet the New JOM Advisors (and Find out More about Their Topics) for 2015}

\section{Lynne Robinson}

$J O M$, in many ways, is the face of the TMS community. Every month, its pages brim with the latest ideas, information, and knowledge that are generously shared to advance the wide range of science and engineering disciplines that TMS serves. The responsibility for filling those pages with quality technical articles falls to the network of $J O M$ volunteer advisors, working closely with their TMS technical committees to ensure that the best and most relevant topics are covered in their respective interest areas every year. As JOM has grown, so have the opportunities to play this important role, with the 2015 editorial year marking a record-setting number of new JOM advisors. The following pages give you a chance to become acquainted with these individuals, as well as the content they are looking for as they develop their topics. For additional information on how you can contribute to $J O M$ as a volunteer or author, visit the JOM website at jom.tms.org or contact Maureen Byko,JOM editor, at mbyko@tms.org.

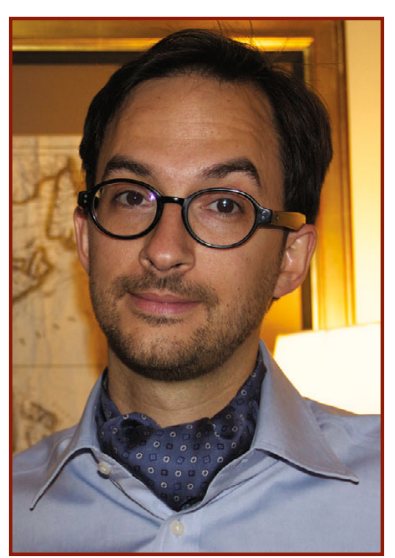

Antoine Allanore

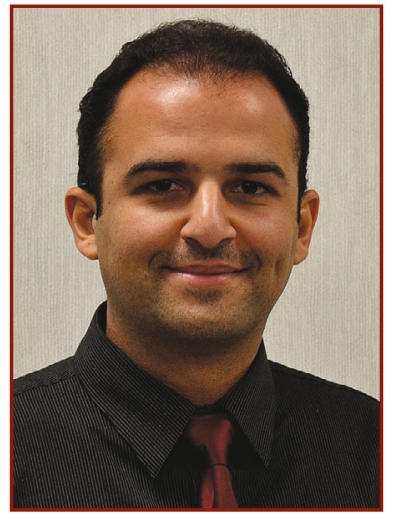

Babak Arfaei

\section{Antoine Allanore}

T.B. King Assistant Professor of Metallurgy, Department of Materials Science and Engineering, Massachusetts Institute of Technology

Process Technology \& Modeling

Committee

\section{Topic Information:}

Control of Interfacial Phenomena during Processing: Modeling and Technology Developments (July 2015)

Manuscript Deadline: March 15, 2015

Allanore noted that this topic has been developed "as a platform of exchange among materials disciplines-including ferrous metallurgy, non-ferrous metals extraction, ore processing, welding and joining, and powder metallurgy — based on common interfacial issues during processing." He is interested in articles that "range from the analysis and description of multi-physics modeling of interfaces to the development of new sensors or methods, at the laboratory or industrial scale, for their control and observation."

\section{About the Advisor:}

"TMS offers an exceptional forum for exchange across disciplines - a necessary condition for the development of future technologies," said Allanore. "From that perspective, being a $J O M$ advisor with the ability to pull from the extraordinary audience involved in TMS and reading $J O M$ is a great opportunity. I hope to show the vitality of the materials extraction and processing field, and help researchers to share their practices and build an even stronger community."

\section{Babak Arfaei}

Research Assistant Professor, Binghamton University/Process Research Engineer,

Universal Instruments

Electronic Packaging \& Interconnection Materials Committee

Topic Information:

Progress with Lead-Free Solders (October 2015)

Manuscript Deadline: June 15, 2015

While this particular technical topic encompasses a wide range of issues regarding electronic packaging, Arfaei said he is particularly interested in papers with a focus on solidification behavior, microstructural aspects, and their correlations to reliability testing and modeling of lead-free solders joints.

\section{About the Advisor:}

"TMS is a great professional organization and I am proud to be part of 


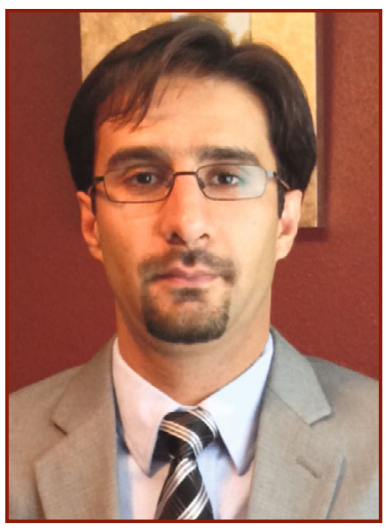

Mohaen Asle Zaeem

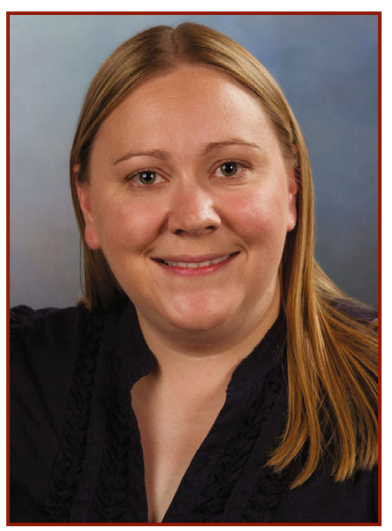

Amy Clarke

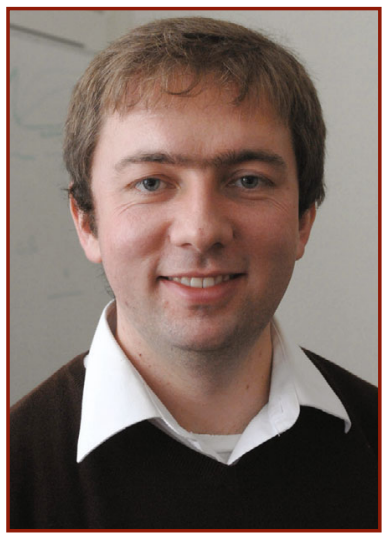

Michael J. Demkowicz

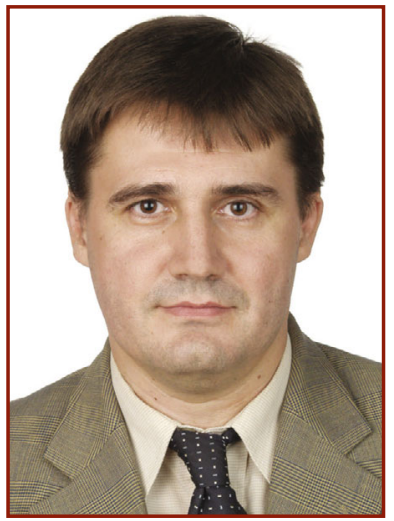

Dean Gregurek it. I have learned a lot over the years from attending TMS meetings and participating in its committees," said Arfaei. "As a JOM advisor, I have the chance to work with colleagues, learn from their research, and encourage more materials scientists to get involved with TMS."

\section{Mohaen Asle Zaeem}

Couch Assistant Professor of Materials

Science and Engineering, Missouri

University of Science and Technology (Rolla)

Solidification Committee

\section{Topic Information:}

Advances in Modeling of Solidification

Microstructures (August 2015)

Manuscript Deadline: April 15, 2015

Asle Zaeem described this topic as "bringing together the recent advances in modeling and simulation of nanoand micro-structural evolution during solidification of metallic alloys." In particular, he is seeking "high quality research articles that focus on modeling tools or numerical algorithms for simulating solidification microstructures."

\section{About the Advisor:}

Asle Zaeem said that this JOM topic closely aligns with his own research interests. "The JOM advisor role has provided me with opportunities to connect with leaders in the fields of solidification and computational materials science and engineering, and has helped me grow my leadership skills," he said.

\section{Amy Clarke}

Scientist, Los Alamos National Laboratory Phase Transformations Committee

\section{Topic Information:}

Phase Transformations and Microstructural Evolution (October 2015)

Manuscript Deadline: June 15, 2015

Clarke highlighted that this JOM topic aligns with the Phase Transformations Committee's signature symposium, marking its third year at the TMS 2015 Annual Meeting \& Exhibition, March 15-19, in Orlando Florida. "We are seeking articles on solid-state phase transformations and microstructural evolution, which are critical to a material's properties and performance," Clarke said. "Studies that couple experiments and computational modeling to improve our understanding of phase transformation mechanisms and microstructural evolution are highly encouraged."

\section{About the Advisor:}

Clarke is taking on the JOM Advisor role after chairing the Phase Transformations Committee. "I look forward to developing new ideas with our committee for JOM topics that will highlight the scientific and technological importance of phase transformations in materials," she said.

\section{Michael J. Demkowicz}

Associate Professor, Department of Materials Science and Engineering, Massachusetts Institute of Technology Chemistry and Physics of Materials Committee

\section{Topic Information:}

New Horizons in Mechanical

Spectroscopy (August 2015)

Manuscript Deadline: April 15, 2015

"My co-editors and I believe that the time is right to revisit mechanical spectroscopy as a promising addition to the modern materials characterization toolbox," said Demkowicz. "JOM is a great venue for bringing mechanical spectroscopy to the attention of the broader structural materials community."

\section{About the Advisor:}

Demkowicz said he will draw from his current interests in "connecting cutting-edge acoustic measurements with multiscale modeling to gain insight into time-dependent materials behaviors" in managing this $J O M$ topic.

\section{Dean Gregurek}

RHI, Technology Center Leoben, Austria Pyrometallurgy Committee

\section{Topic Information:}

Metallurgy: Energy and Environmental Issues (May 2015)

Manuscript Deadline: January 15, 2015

Sustainability in Metallurgy (September 2015)

Manuscript Deadline: May 15, 2015

Lead and Zinc Metallurgy (September 2015)

Manuscript Deadline: May 15, 2015 
"We want to produce $J O M$ issues with high-quality international input," said Gregurek. "We are interested in new developments and ideas in pyrometallurgy, not only on the metallurgical process side, but also regarding interaction with refractories and furnace integrity. Our topics should be interesting reading material for experts, as well as a basis for discussion and inspiration for future work and improvements."

\section{About the Advisor:}

Gregurek said that while his company, $\mathrm{RHI}$, is already heavily involved in process developments and pyrometallurgical challenges, he sees his JOM advisor role as enabling him to "further broaden the horizon and get new ideas for our work." He noted that the main goal of the Pyrometallurgy Committee for its JOM topics is "to provide excellent scientific reviews for the submitted papers, partly by inviting international reviewers and experts in their fields. In this way, we hope to increase the impact factor of the journal in the coming years," he said.

\section{Satoshi Hirosawa}

Director, Elements Strategy Initiative Center for Magnetic Materials, National Institute for Materials Science, Japan Magnetic Materials Committee

\section{Topic Information:}

Permanent Magnets beyond Nd-Dy-Fe-B (June 2015)

Manuscript Deadline: February 15, 2015

"I am seeking overviews of big national projects and topical articles on recent investigations directed toward discovery of new permanent magnets covering a wide range of materials, from Dy-free Nd-Fe-B to non-rare earth magnets," said Hirosawa.

\section{About the Advisor:}

Hirosawa has been working on permanent magnet materials since the 1980 s, and is acquainted with prominent researchers in both academia and industry. Noting that he "enjoys collecting good articles on permanent magnet materials," Hirosawa said, "I recently joined the TMS Magnetic Materials Committee and was encouraged to take responsibility for this particular topic in JOM."

\section{Peter Hosemann}

Associate Professor, Nuclear Engineering Department, University of California, Berkeley

Nanomechanical Materials Behavior Committee

\section{Topic Information:}

Nanomechanical Measurements in Harsh

Environments (December 2015)

Manuscript Deadline: August 15, 2015

Hoseman said that this technical topic will examine nanomechanical testing techniques in specific environments "be it low or high temperatures," as well as for liquid or radiation impacts on a range of materials.

\section{About the Advisor:}

Hoseman said that his experiences as a TMS member have benefited him in his daily research. "It's natural for me to volunteer by contributing my expertise to help TMS explore interesting topics like the one I am engaged with as a JOM advisor," he said. "I hope this effort will help to foster communications and discussions on this topic and grow the research community."

\section{Marian S. Kennedy}

Associate Professor, Department of Materials Science and Engineering, Clemson University

Mechanical Behavior of Materials Committee

Topic Information:

Stability of Nanomaterials (December 2015)

Manuscript Deadline: August 15, 2015

"Nanostructured materials have demonstrated many mechanical property improvements over their coarse-grained counterparts," said Kennedy. "However, the property profiles of these materials can be altered during grain growth or phase transformation at low temperatures or under modest applied loads." This JOM topic will address issues of nanomaterial instability by focusing on recent thermodynamic and kinetic stabilization strategies.

\section{About the Advisor:}

Kennedy noted that the topic will be guest-edited by Brad Boyce, Sandia National Laboratories, and Suveen Mathaudhu, University of California, Riverside. "As symposium organizers, they saw this emerging topic as both needed and vital for the community." said Kennedy. "As the JOM

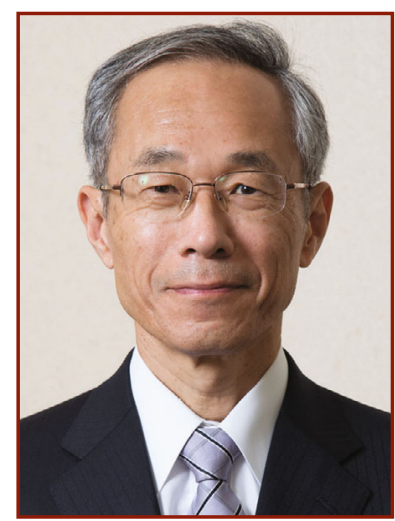

Satoshi Hirosawa

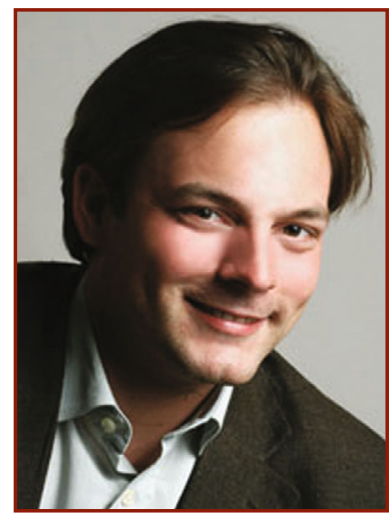

Peter Hosemann

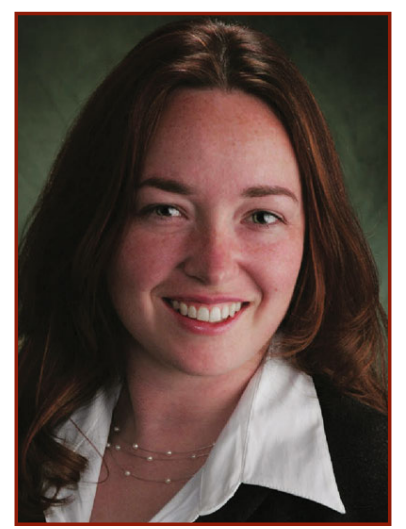

Marian S. Kennedy 


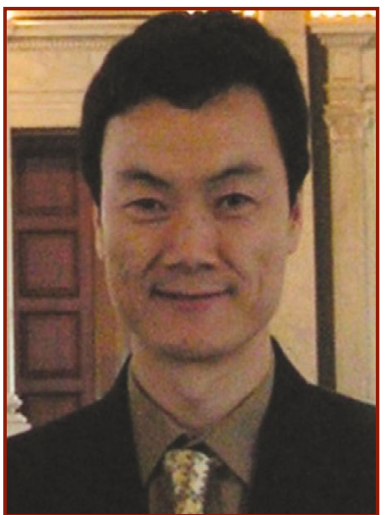

Bowen $\mathrm{Li}$

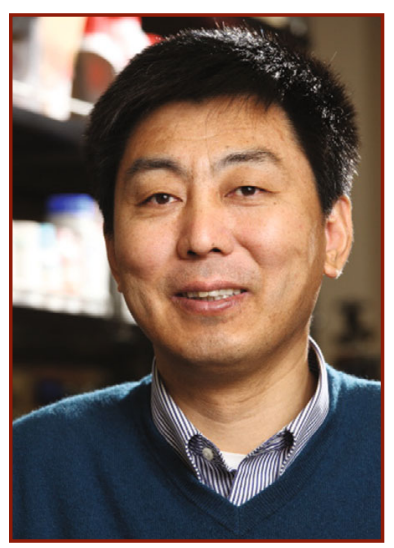

Xiaodong Li

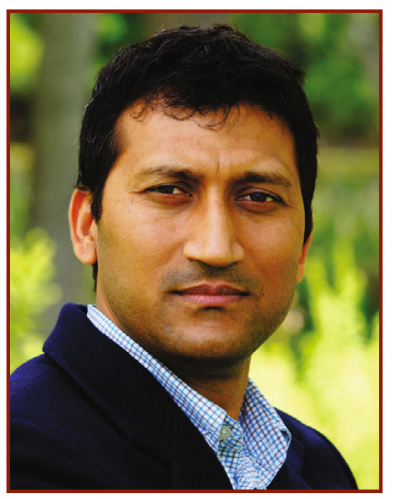

Amit Pandey

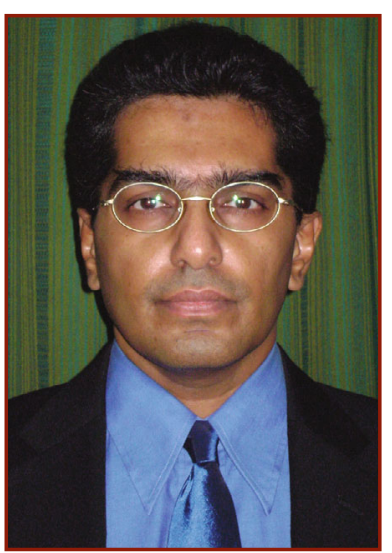

Muralidharan Paramsothy advisor, my role is to help all guest editors from our committee navigate the JOM process. I am also delighted that this topic aligns strongly with my research interests in the stability of nanolaminate under sliding wear in elevated temperatures."

\section{Bowen Li}

Research Associate Professor, Department of Materials Science and Engineering, Michigan Technological University Materials Characterization Committee

\section{Topic Information:}

\section{Characterization of Advanced Mineral} Materials (February 2015)

Manuscript Deadline: October 15, 2014

"We are seeking articles that demonstrate novel research achievements related to mineral synthesis, separation, extraction, analysis, characterization, surface treatment, and applications in downstream materials," said Li.

\section{About the Advisor:}

Li offers more than 25 years of experience focused on the processes and characterization of industrial minerals and materials. "Being a $J O M$ advisor is a great opportunity to contribute to the community of minerals and materials, while learning new knowledge and methodologies from the article authors," he said.

\section{Xiaodong Li}

Rolls-Royce Commonwealth Professor, University of Virginia

Nanomechanical Materials Behavior Committee

\section{Topic Information:}

Nanomechanical Behaviors of Biomaterials (April 2015)

Manuscript Deadline: December 15, 2014

Effects of Interfaces on Mechanical Properties of Composites (July 2015) Manuscript Deadline: March 15, 2015

Nanomechanical Measurements in Harsh Environment (December 2015)

Manuscript Deadline: August 15, 2015

While the three JOM topics that he is advising in 2015 explore different interest areas, Li said that the type of articles that he is seeking share common characteristics. "We are looking for original research articles that present breakthroughs and step-changes, as well as review articles that summarize the state of the art in their respective areas," he said.

\section{About the Advisor:}

I have enjoyed reading $J O M$ since joining TMS in 1998," said Li. “After I stepped down as Nanomechanical Materials Behavior Committee Chair, I saw that being a JOM Advisor was another way to continue to serve TMS."

\section{Amit Pandey}

Development Lead (Reliability Division), Rolls Royce LG Fuel Cell Systems Inc Advanced Characterization, Testing, and Simulation Committee

\section{Topic Information:}

In-Situ Mechanical Testing in Electron Microscopes (August 2015)

Manuscript Deadline: April 15, 2015

"Most high temperature systems, in particular solid oxide fuel cells (SOFCs), are comprised of a thin ceramic multilayer," said Pandey. "The in-situ response and properties of these layers are important for understanding longterm reliability and development of life prediction models." For this $J O M$ topic in particular, Pandey said, "I am looking for articles conveying that in-situ should not be confined to studies related only to size effect."

\section{About the Advisor:}

Providing an avenue for networking within a specialized research community is one of several opportunities that Pandey said has been opened to him as a JOM advisor. "At the same time, this experience has helped me better understand the challenges of testing brittle materials at a smaller scale," he said.

\section{Muralidharan Paramsothy}

Associate Faculty, School of Science and

Technology, Singapore Institute of

Management University

Composite Materials Committee

\section{Topic Information:}

Futuristic Nanomaterials and

Composites (December 2015)

Manuscript Deadline: August 15, 2015

Paramsothy said the topic will encompass articles on synthesis, structure, properties and application 
of nanomaterials and composites, "preferably with an overall broad range of application."

\section{About the Advisor:}

"Being a JOM advisor allows me to network at higher levels," said Paramsothy. "I strongly advocate that the more researchers we have who are willing to share their thoughts, the higher the probability that really good concepts will come to light and advance the field."

\section{Zhiwei Peng}

Research Assistant Professor, Michigan

Technological University

Pyrometallurgy Committee

Topic Information:

Metallurgy: Energy and Environmental Issues (May 2015)

Manuscript Deadline: January 15, 2015

Sustainability in Metallurgy (September 2015)

Manuscript Deadline: May 15, 2015

Lead and Zinc Metallurgy (September 2015)

Manuscript Deadline: May 15, 2015

\section{About the Advisor:}

With professional interests focused on extractive metallurgy and electromagnetic energy, Peng said he is looking forward to reviewing papers for the three topics that he is responsible for and anticipates "witnessing more exciting developments in metallurgy and clean energy."

\section{Ramprashad Prabhakaran}

Research Associate, Pacific Northwest

National Laboratory

Nuclear Materials Committee

\section{Topic Information:}

Materials Degradation in Light-Water

Reactors (November 2015)

Manuscript Deadline: July 15, 2015

Prabhakaran noted that the overall theme of the November 2015 issue of $J O M$ is "Materials for Energy and Extreme Environments." The topic he is responsible for will contribute to this exploration through "articles, both experimental and simulation, that focus on the radiation effects on austenitic stainless steels; aging, fatigue and other degradation issues; and advanced alloys that have superior radiation resistance."

\section{About the Advisor:}

"Globally, significant efforts are ongoing to meet the growing energy demand with the increased use of nuclear energy. Extensive work is being performed to develop materials and fuels for current and advanced nuclear reactors," said Prabhakaran. "As a JOM advisor, my role is to provide a platform for researchers to present and discuss their work, in addition to sharing challenges and solutions with the professional community."

\section{Ma Qian}

Professor and Deputy Director, Centre for Additive Manufacturing, Royal Melbourne Institute of Technology

Powder Materials Committee

Topic Information:

Metal Powder for Additive

Manufacturing (3D Printing) (March 2015)

Manuscript Deadline: November 15, 2014

Qian said he is interested in articles that deal with all aspects of metal powder characteristics relevant to 3D metal printing or additive manufacturing of metals.

\section{About the Advisor:}

Qian described his role as $J O M$ advisor as a unique opportunity to help promote and shape powder materials science and engineering. "I look forward to being a useful advisor and friend to all of our TMS members who are interested in this field," he said.

\section{Balasubramaniam Radhakrishnan}

Senior Research Staff, Oak Ridge National Laboratory

Computational Materials Science and Engineering Committee

\section{Topic Information:}

Modeling of Microstructure Evolution during Additive Manufacturing (March 2015)

Manuscript Deadline: November 15, 2014

Within the March 2015 JOM overall technical theme of additive manufacturing, Radhakrishnan will be highlighting articles that describe current efforts in simulating the evolution of structures at the nano- and microscale during the complex thermal cycles encountered during additive

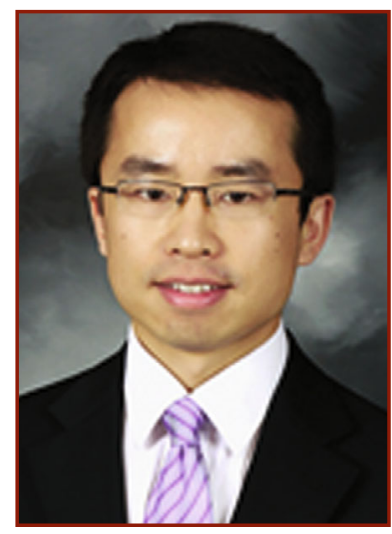

Zhiwei Peng

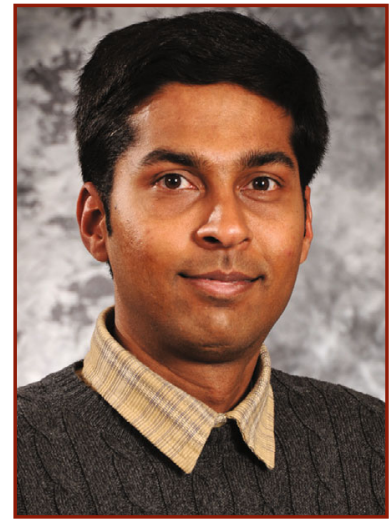

Ramprashad Prabhakaran

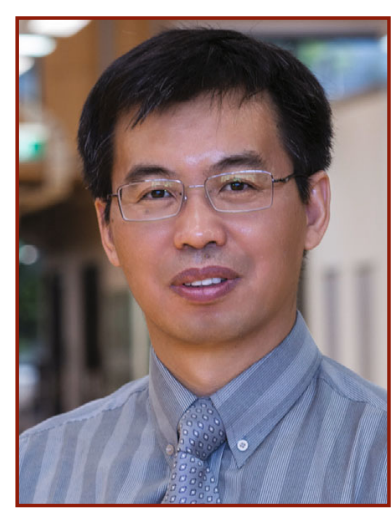

Ma Qian

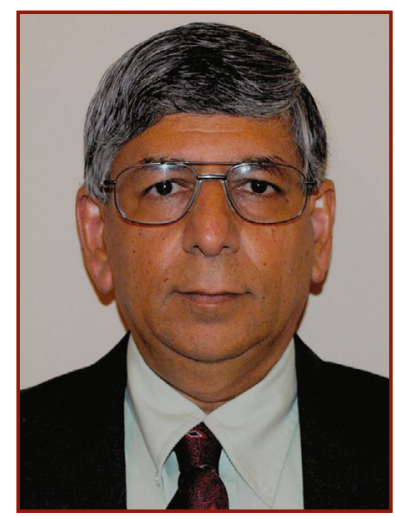

Balasubramaniam Radhakrishnan 


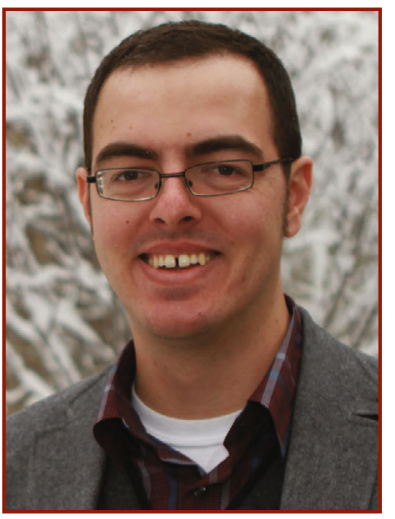

James Saal

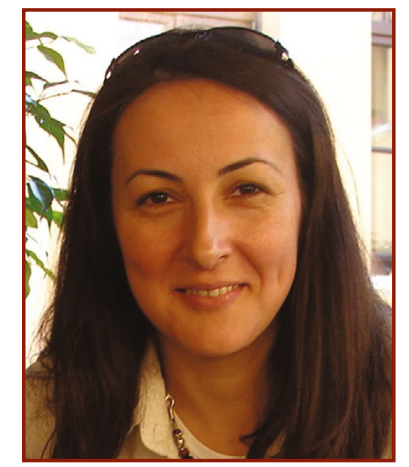

Candan Tamerler-Behar

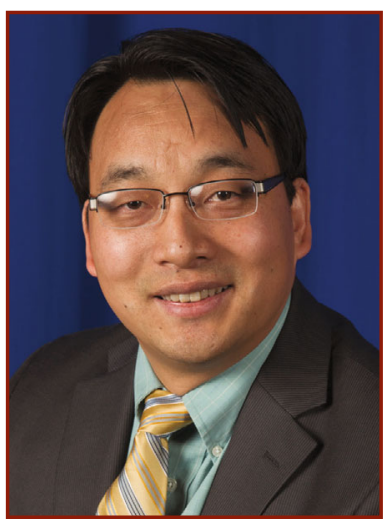

Jian Wang manufacturing. "If such models can be developed and validated, then they will play a key role in designing alloys for additive manufacturing and tailoring their properties through proper choice of process parameters and alloy compositions." he said.

\section{About the Advisor:}

Radhakrishnan said that he is looking forward to interacting with investigators from throughout the world who share his interests in enhancing the use of current and evolving high performance computational tools, algorithms, and theory that can be applied to model microstructure evolution during additive manufacturing of structural alloys.

\section{James Saal}

Materials Design Engineer, QuesTek

Innovations, $L L C$

Magnesium Committee

\section{Topic Information:}

Age-Hardenable Microalloying in Magnesium (October 2015)

Manuscript Deadline: June 15, 2015

For this topic, Saal is interested in experimental, theoretical, and review papers that explore why microalloying in magnesium produces specific hardening responses, particularly with regards to choices in chemistry and examination of resulting microstructures.

\section{About the Advisor:}

"I volunteered to be a JOM Advisor to foster discussion on a topic that I believe is important to the advancement of magnesium alloys and in which I have personal scientific interest," Saal said. "I look forward to the responsibilities and duties of producing an issue of a major materials journal."

\section{Candan Tamerler-Behar}

Wesley G. Cramer Associate Professor, Mechanical Engineering Department; Director, Biomaterials and Tissue Engineering Track; Director, Bioenabled and Biomimetic Materials, Bioengineering Research Center, University of Kansas Biomaterials Committee

\section{Topic Information:}

Surfaces and Biointerfaces (April 2015) Manuscript Deadline: December 15, 2014

"Biological materials exhibit complex structure and property relationships on multiple length scales with rich hierarchical organization," said TamerlerBehar. "Understanding interfaces in biological materials and harnessing these design strategies to develop biomimetic, bioinspired, and bioenabled materials will facilitate accomplishing functionally integrated materials for a wide range of application areas." To advance this understanding, Tamerler-Behar said that she plans to explore the JOM topic through articles that "bridge fundamental understanding at the soft and hard biomaterial interfaces to cutting edge applications for diverse technological areas."

\section{About the Advisor:}

"The interaction of materials and biological systems is a rapidly growing, interdisciplinary frontier in materials science and engineering with boundless possibilities," said Tamerler-Behar. "As JOM advisor, I am very excited to be developing a technical theme that will reach a diverse group of readers and continue to expand the interest in biomaterials, with a focus on the critical challenge of interfaces.'

\section{Jian Wang}

Technical Staff Member, Los Alamos National Laboratory

Nanomechanical Materials Behavior Committee

\section{Topic Information:}

Nanomechanical Behaviors of Biomaterials (April 2015)

Manuscript Deadline: December 15, 2014

Effects of Interfaces on Mechanical

Properties of Composites (July 2015)

Manuscript Deadline: March 15, 2015

Wang's current research focus is the quantitative exploration of structureproperties relationships in structural and nanostructured materials by combining microscopic characterization and modeling at the multi-scale. He noted he will leverage this interest in seeking review articles for his JOM topic.

\section{About the Advisor:}

Wang has been an active TMS volunteer for several years, saying, "The most positive aspect of volunteering is interacting with accomplished people in the field and developing my own abilities to contribute to the greater good of society." 